\title{
A Thirteenth-Century Dodecahedron in Central Anatolia: Geometric Patterns and Polyhedral Geometry
}

\author{
Sibel Yasemin Özgan ${ }^{1} \cdot$ Mine Özkar ${ }^{1}$
}

Published online: 22 May 2017

(C) Kim Williams Books, Turin 2017

\begin{abstract}
The lace-like geometric patterns of medieval Seljuk art cover mostly planar surfaces, extending to the borders in a uniform manner. Some are applied on engaged columns, interiors of concave surfaces, and exteriors of half-spheres. There are also rare examples on faces of polyhedra. The construction of either the tessellation or a polyhedron is already demanding, and combining the two poses an additional mathematical challenge. One such case is that of the tomb of Gömeç Hatun in Konya, where a dodecahedral column capital was, as evidence suggests, covered with a mosaic tiling. A visual geometric investigation of the capital and its historical precedents sheds light on how the artisan's knowledge of polyhedral and polygonal geometries may have been essential in the design and its materialization.
\end{abstract}

Keywords Design analyses · Design computation · Geometric patterns · Seljuk art · Platonic solids (dodecahedron) $\cdot$ Polyhedron/polyhedra $\cdot$ Tessellations/tilings

\section{Introduction}

The earliest mention of polyhedral geometry is found in ancient Greek sources, yet archaeological findings show that the mathematical and artistic inquiry into polyhedra can date back to as early as prehistoric times (Kappraff 1992: 34). This knowledge of conceptualizing and constructing polyhedra was either sustained or continually rediscovered in following centuries and across geographies. Albeit sporadically, polyhedra can be seen in the medieval Islamic world as decorative elements of building facades and interiors. In most of the instances from thirteenth-

Sibel Yasemin Özgan

sibel.ozgan@itu.edu.tr

Mine Özkar

ozkar@itu.edu.tr

1 Faculty of Architecture, Istanbul Technical University, Taskisla, 34437 Istanbul, Turkey 
century Anatolia, surfaces of polyhedra are ornamented with geometric patterns which are characteristic of architectural monuments of the region at that time. While the making of a polyhedron with actual building materials already requires substantial knowledge of its geometry, these instances attest to the double challenge faced by the craftsmen and to their possibly integrated knowledge of polygonal and polyhedral geometry.

Patterns were often adapted to varying kinds of continuous surfaces, curved or flat, and designed with the boundary of this surface in mind. In the case of the polyhedron with patterns, the bounded surfaces are the polygon faces of the solid that are also connected as if a continuous surface. If the design of a polyhedron with patterns on its surfaces implies a thought-out relation between the pattern geometry and the polyhedral geometry, this involves for the craftsman, at least a visual/ spatial, if not mathematical, comprehension of the geometry of the solid and that of a suitable tessellation in relation to it.

One particular instance of ornamented polyhedra is the Tomb of Gömeç Hatun ${ }^{1}$ in Konya, Turkey. Tombs are a common building type in Seljuk architecture, but that of Gömeç Hatun, dated 1270, is of a unique form (Fig. 1). It is an iwan ${ }^{2}$ with a vaulted ceiling, more than eleven meters in height; the rectangular plan is about eight meters in width and nine meters in length. Additional to the curious iwan form, the two small polyhedra, one on each side of the iwan, appear to be dodecahedra in their current state. The dodecahedron is yet another uncommon form in Seljuk architecture. Moreover, these dodecahedra display remnants of mosaics hinting at the existence of a tiled pattern on their faces. Based on these qualities, this rare and little known building adds to our understanding of the practice of geometric knowledge in Anatolian architectural heritage. The material realization of geometric designs and polyhedra is seldom addressed in research on the mathematics of patterns but is reliant on the knowledge of symmetries of shapes and the planar development of solids.

\section{The Dodecahedron of the Tomb of Gömeç Hatun}

The iwan of the tomb sits on the stone foundation enclosing the crypta. Stone masonry is used in the lower half of the iwan then shifts to brick masonry in its top portions and the vault. An elaborate stone portal with a pointed arch frames the iwan in the front. Portals are the very ornate gates to otherwise modest structures and are typical in Seljukid public buildings such as madrasahs, mosques, and caravanserais. The ornamentation on the tomb of Gömeç Hatun is found solely on the portal as well. The stone seems to have been covered in part with square-shaped brick tiles.

The historic tomb has undergone restoration several times, most recently in 2008. The restored version features two irregularly plastered polyhedra (Fig. 2) on top of two engaged columns of the front portal. These solids, although irregular in current form, seem to be dodecahedra with twelve pentagonal faces. Still, the source for this

\footnotetext{
${ }^{1}$ Gömeç Hatun was the wife of the Seljukid Sultan Kılıçarslan and the mother of the subsequent sultan.

2 An Iwan (Eyvan in Turkish) is a hall walled on three sides, with one end entirely open.
} 

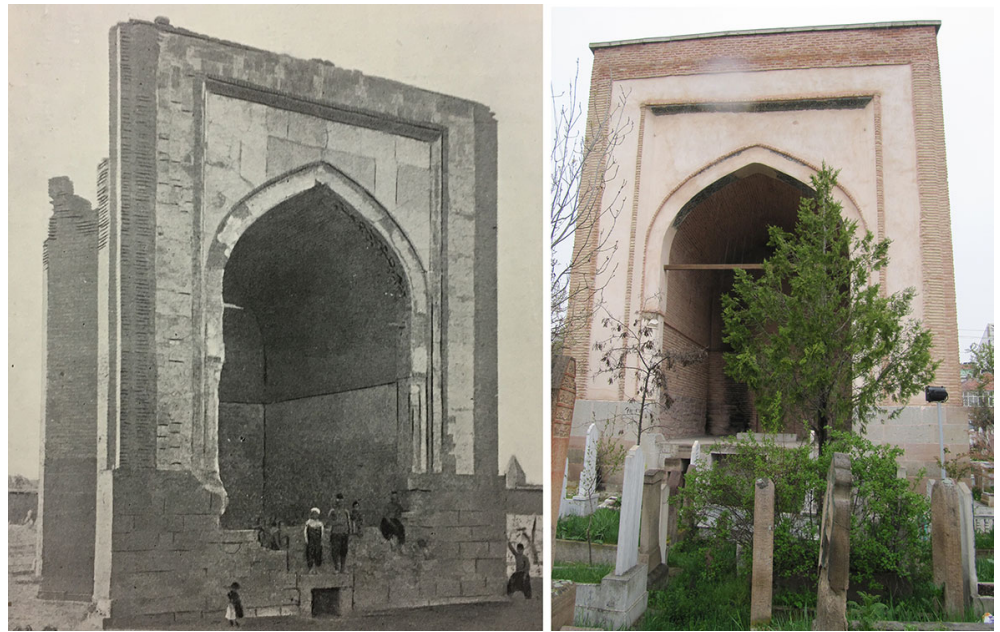

Fig. 1 Left an old photo of the tomb of Gömeç Hatun before the restoration (Photo: Pace 1926: 379); right the current condition of the monument
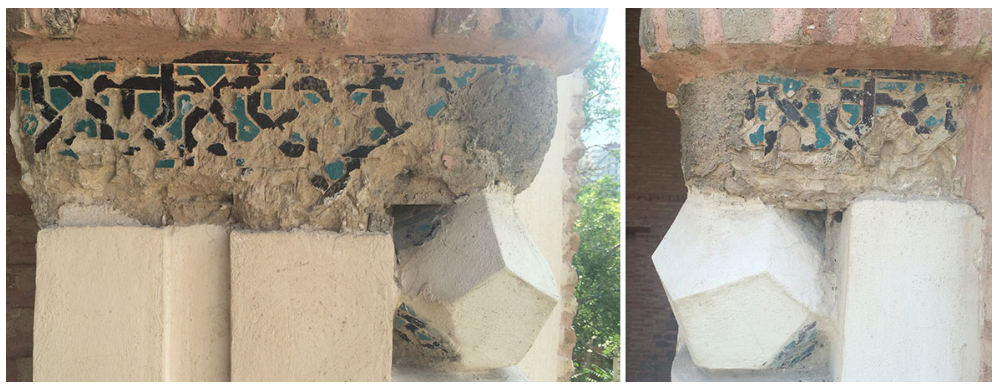

Fig. 2 The dodecahedron column capital in detail

restitution is not clear. There is no written acknowledgement of any dodecahedra, in either in the reports written prior and posterior to the latest restoration of the tomb (Dazkirlı 2008), or in the literature on the tomb. Historical references on ancient Seljuk tombs (Sözen 1968: 184-188; Önkal 1996: 338-342) highlight the unusual architecture of the monument, but they do not provide a detailed analysis on the column capitals. Earlier records on the tomb (Uğur 1937: 567-570; Yetkin 1961: 357-360; Meinecke 1976: II, 355-358) and the restoration project report (Dazkırlı 2008) present historical photos in which extremely damaged original capitals are visible. Although the details are difficult to decipher, the capitals allude to dodecahedral geometry, and the current restitution could have easily been based on these photographs. Precedents and a historical context corroborate the assumption that a thirteenth-century construction of a dodecahedron was possible in Konya. 


\section{On the Artisan's Knowledge of Polyhedra in Medieval Anatolia}

Polyhedra are historically one of the most studied forms in mathematics and arts. The first recorded theory of polyhedral geometry goes back to Euclid's Elements, written circa $300 \mathrm{BC}$. Archaeological discoveries of carved stone objects from Scotland reveal that a conducive understanding of polyhedral geometry existed even in Neolithic periods (Lundy 2010: 8). Albrecht Dürer's Unterweysung der Messung ("On Teaching Measurement with Compass and Straightedge") (1525) is the earliest reference for drawing the developed surfaces (or nets) of polyhedra (O'Rourke 2013: 77), establishing a link between two-dimensional geometry and the making of the solids (Malkevitch 2013: 57). Earlier than Dürer however, mathematicians of the Islamic world, in a golden age of science lasting from the eighth century to the thirteenth century, had access to translations of Elements along with other primary works of the ancient Greeks, and they expanded knowledge of the concept and theory of polyhedral geometry. Texts on astronomy, optics, law, and linguistics provided new insights into mathematics, paving the way to major explorations in the field of geometry during that period (Scriba and Schreiber 2015: 171-189).

Among key features of medieval Islamic art is the use of intricate polygonal geometry in patterns on architectural surfaces. It is well established in the literature that the rich corpus of unique patterns were mostly created with a simple and intuitive method of using a compass and a straightedge, building on variations emerging from the interlaced circles (Hankin 1925: 371-373; Critchlow 1976; Lee 1987: 182-197). Understood as such, earlier examples are usually periodic (Bakırer 1999: 42-69). Alternatively, patterns are analyzed and understood as tiling, and some are not periodic (Necipoglu 1995: 231-283; Lu et al. 2007: 1106-1110).

Not only the design but also the application of these lace-like patterns on all kinds of architectural surfaces very much relied on the knowledge and innovative use of polygonal geometry. But it is not entirely clear who this knowledge should be attributed to between artisans and mathematicians. Sarhangi (2008: 523) highlights the fact that some specific designs necessitated the collaboration of artisans and mathematicians and cites the mathematician-astronomer Abu'lWafā Al-Būzjānī’s On the Geometric Constructions Necessary for the Artisan (ca. 940-998) as a rare but key reference for the mathematician's indirect involvement in architectural practice. ${ }^{3}$ In addition to describing how to construct regular polygons, providing some reference for two-dimensional pattern geometry, AlBūzjān̄̄'s text gives instructions for deriving the measurements for dividing the sphere into twelve equal pentagons towards achieving a dodecahedron (Scriba and Schreiber 2015: 183). This treatise is the significant evidence to the level of knowledge about the construction of polygons and polyhedra as early as the tenth century and in the context of artisans' works. Although Baghdad is not in Anatolia, Alpay Özdural (1995: 55) links this treatise to the knowledge of geometry in subsequent building traditions of Anatolia in the later centuries. It is

\footnotetext{
3 In the acknowledged relation between the arts of building and mathematics, geometricians developed visual instructions to artisans in addressing geometrical challenges. With reference to Omer Khayyam's writings, Özdural (1995: 55) reports that mathematicians and artisans collaborated through special meetings and discussed design problems.
} 
possible to deduce that an artisan who applied polygonal geometry on surfaces had some access to this knowledge, perhaps indirectly, or tacitly through practice informed by earlier generations. An understanding of how to construct solids, albeit at another, very large scale, was also required to build the three-dimensional structures of domes and vaults.

Several archaeological items from the medieval Islamic world are evidence of artistic inquiry into Platonic solids and other polyhedra. An eleventh-century necklace of Seljuk origin from Iran, currently in the collection of the Metropolitan Museum of Art in New York City, is one example with dodecahedral gold beads. ${ }^{4}$ Other small polyhedral objects, on display in the collection of the Museum of Seljuk Civilisation in Kayseri, Turkey, ${ }^{5}$ are made of bronze for use as decorative weights in trading. These are a testament to the knowledge of constructing polyhedra by the cultures that produced the geometric patterns on architecture. Moreover, polyhedra can be occasionally seen as part of architectural elements, as in the case of the tomb of Gömeç Hatun. The only other dodecahedral architectural elements from the region are found in the mihrab ${ }^{6}$ in the Misri Mosque in Afyon. These are coeval with the tomb of Gömeç Hatun but differ in construction: each is made up of twelve monochrome glazed tiles of regular pentagon shape (Fig. 3).

The conception and building of the polyhedron is a challenge in its own right for any artisan at the time. Sarhangi (2008: 518-519) reports that Al-Būzjānı̄’s illustrations translate spherical constructions of polyhedra, including pentagonal ones, to flat images. Once the cutter knows the dihedral angle arcos $(-1 / \sqrt{ } 5)=116.56$, and hence the angle to taper the corners with, it is possible and straightforward to cut the edge-transitive dodecahedron out of a solid cube (Fig. 4).

In contrast to the construction in the digital model, physically cutting the dodecahedron out of a solid cube requires supports to hold the irregular solids that emerge as subtraction continues. If the dihedral angle is not utilized, the artisan can at best estimate the angles and achieve a faulty irregular dodecahedron as in the restituted example in the tomb of Gömeç Hatun.

Even with differences in material, there are stylistic similarities between the ornamental details of the tomb and the mosque in question; and both buildings may have been products of the same atelier (Meinecke 1976: I, 35-45). The monochrome glazed tile surfaces of the dodecahedra in the Misri Mosque are suggestive of an additive method where regular pentagons come together to bound the volume of a regular dodecahedron. There is unfortunately no evidence to corroborate this method for the Misri Mosque. Nonetheless, the description in Euclid's Elements offers an additive method (Cromwell 1999: 69). In that description, tapered prisms are added onto a solid cube from the outside to form a dodecahedron. The dihedral angle ensures the regularity of the polyhedron (Fig. 5).

\footnotetext{
4 The Metropolitan Museum of Art, Online Collection Catalog, http://www.metmuseum.org/art/ collection/search/454086? sortBy=Relevance\&amp; ft=gold+necklace\&amp;offset=100\&amp;rpp= 100\&amp;pos=113. Accessed 29 Oct 2016.

5 See: Kayseri Museum of Seljuk Civilization, Online Collection Catalog, http://www.selcuklumuzesi. com/ustmenu.asp?id=9\&euid=2\&sid=9. Accessed 29 Oct 2016.

6 A Mihrab is a niche in the wall of a mosque. It indicates the direction of Mecca.
} 

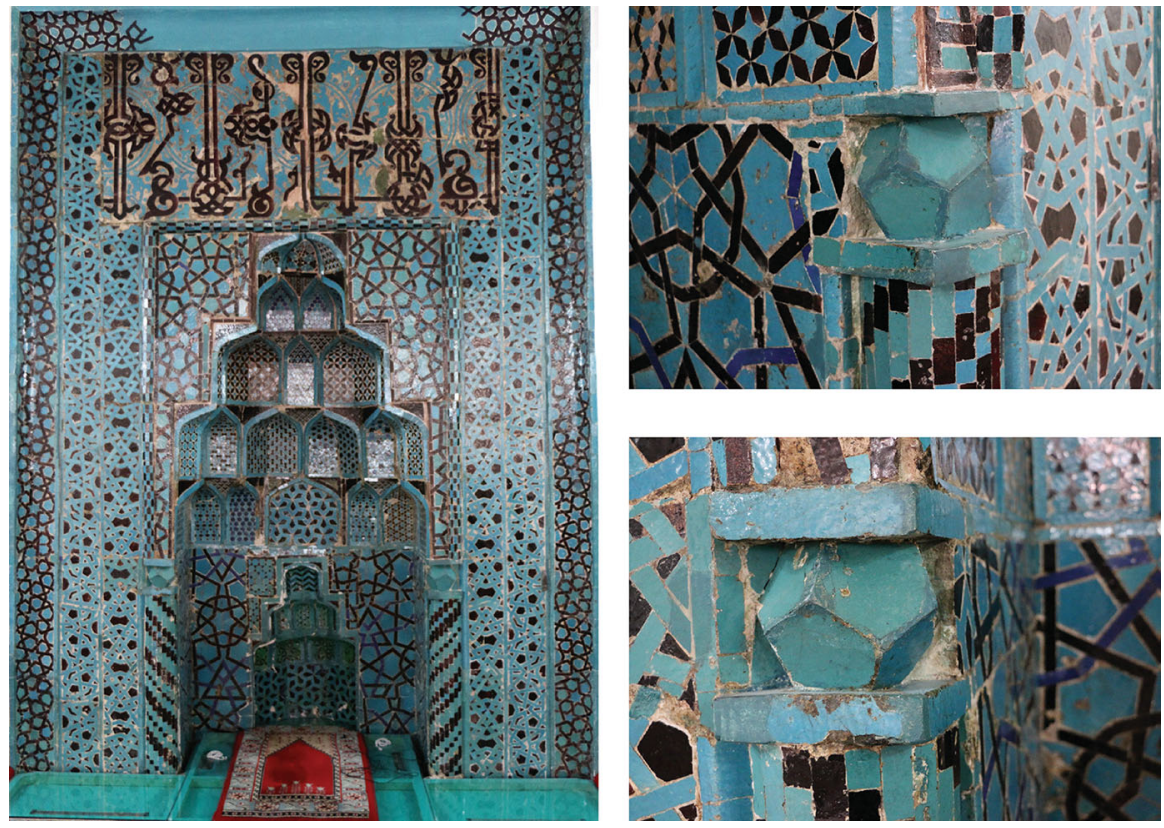

Fig. 3 The Mihrab of the Afyon Misri mosque and the dodecahedron on top of the engaged column

Both methods are valid in appropriate contexts. Meinecke (1976: I, 45) attributes the tiles of the Misri mosque to an Iranian artisan named Muhammad Tusi and his atelier in the region of Konya. Stylistic features (Meinecke 1976: II, 355-357) indicate that the legacy of the Tusi atelier may have been involved in the making of the tomb of Gömeç Hatun. This lends support to the hypothesis that the artisans who worked in the construction of the tomb of Gömeç Hatun could have had knowledge of and experience with dodecahedral geometry, as the atelier had worked with the solid before in the Misri Mosque. The construction of a dodecahedron around an inscribed cube or as cut out of a cube suggests some knowledge of "nets", that is, the planar development of polyhedra.

\section{Geometric Patterns and Polyhedral Geometries}

In the restored tomb of Gömeç Hatun, traces of tile mosaic remain on some parts of the polyhedron surfaces, revealing that each solid was once covered with a pattern. The turquoise and black coloring of the tiles and meticulous detailing, and that there are more than four different surfaces, albeit small, with the same geometric pattern repeating, provide evidence that they are likely to be original. Some records before the last restoration (Meinecke 1976: II, 356; Sözen 1968: 184-188) refer to traces of tile mosaic on the column capital surfaces. 

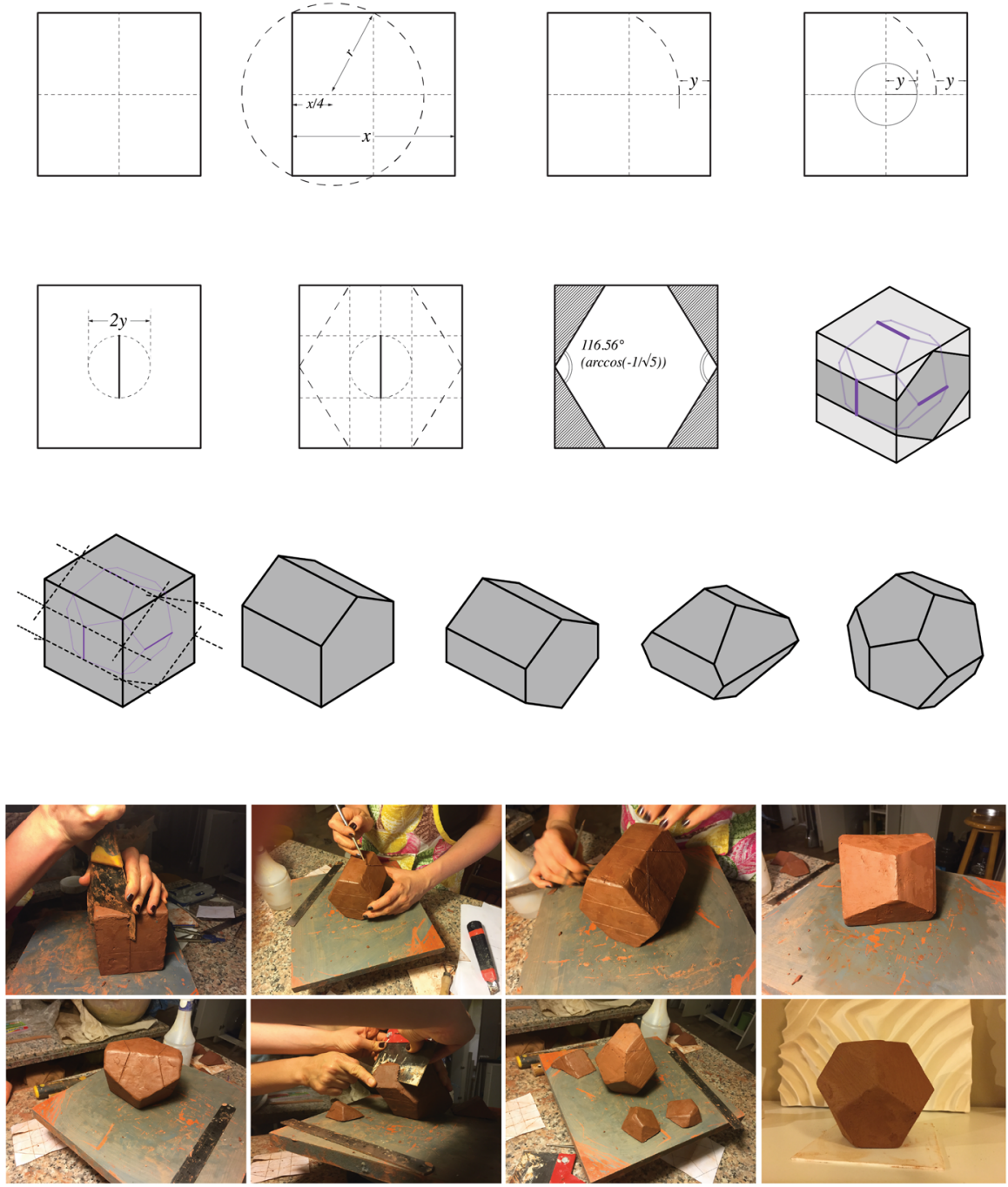

Fig. 4 Above instructional drawings to acquire the dihedral angle and mark the square with guides for cutting, the digital model of the step-by-step tapering of the edges of a solid cube to reveal a regular dodecahedron; below the actual making of a dodecahedron out of clay

As mentioned before, there are seldom instances in Anatolian architecture where patterns adorn surfaces of polyhedra. There are no other patterned dodecahedra but at least three examples of pattern covered cuboctahedra from roughly the same time and region, attesting to a tradition of crafting patterns on polyhedron faces (Fig. 6). The three cuboctahedra examples are dated to consecutive decades of the thirteenth 

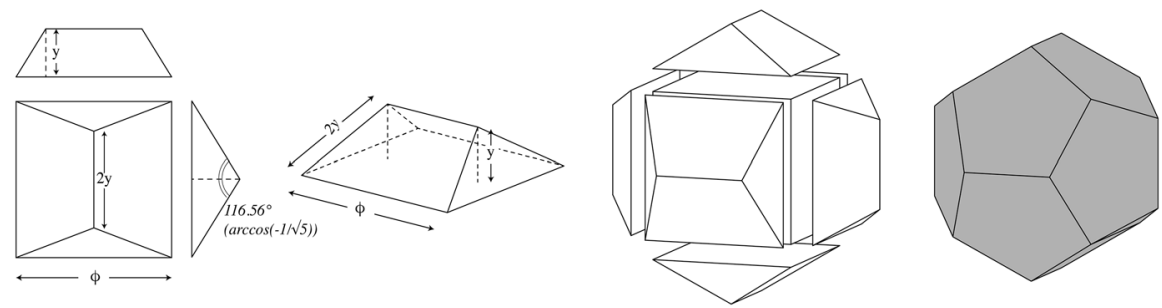

Fig. 5 The construction of a dodecahedron as adapted from Cromwell (1999: 69)

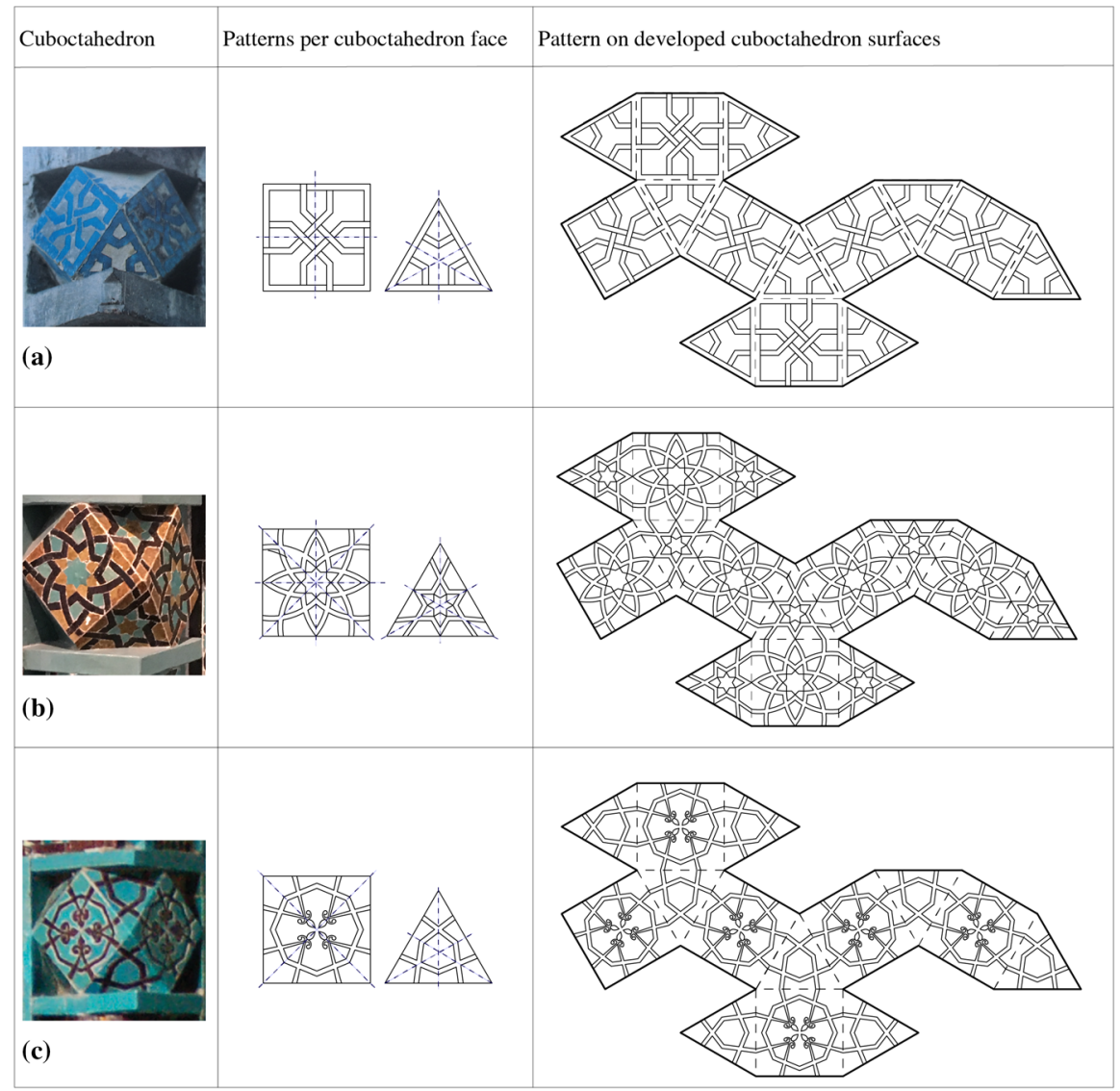

Fig. 6 Detailed analyses on the patterned cuboctahedron examples. a The cuboctahedron column capital in the portal decoration on the Şifaiye Madrasah in Sivas, Turkey (Photo from Ögel 1994: 67, published by AKBANK); b The cuboctahedron column capital in the mihrab from the Beyhekim Mosque; c The cuboctahedron column capital in the Mihrab from the Eşrefoğlu Mosque

century: Şifaiye Madrasah 1217-1220, from Sivas; Beyhekim Mosque 1270-80, originally from Konya, currently in Berlin Museum of Islamic Art; and Eşrefoğlu Mosque 1296-1300, from Beyşehir near Konya. 
Fig. 7 The planar development of a cuboctahedron is extendable through its basic units
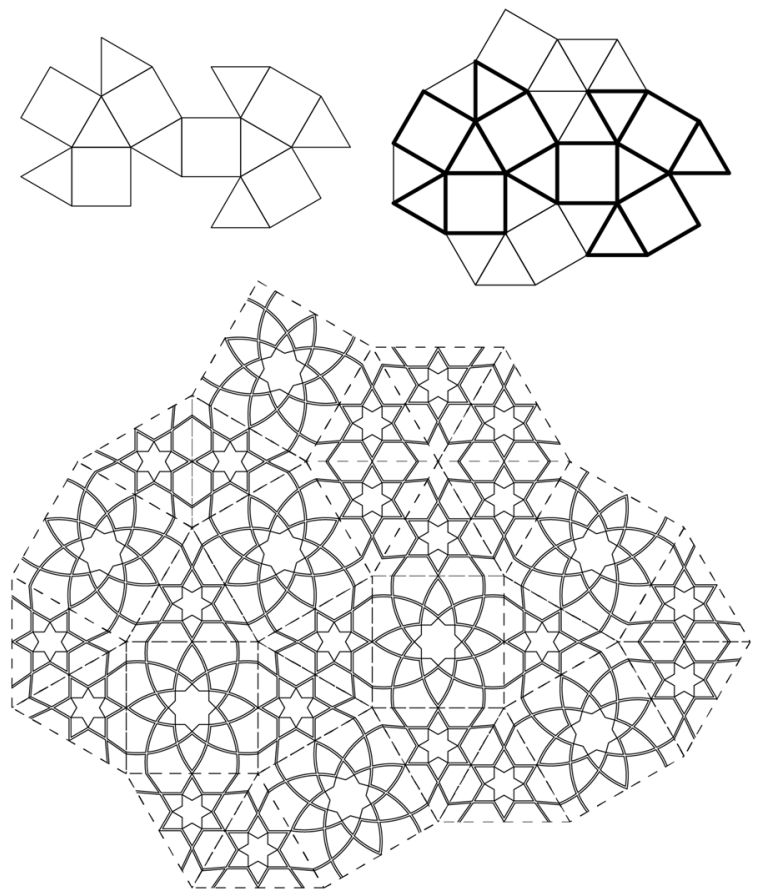

The Beyhekim and Eşrefoğlu cuboctahedra are later than those of the tomb of Gömeç Hatun but share the tile mosaic technique unique to the region ${ }^{7}$ attributed to the tradition of the Tusi Atelier. In the tile mosaic technique, colored and glazed tiles are first assembled together on a flat surface and then applied to the surface (Rigby 2005: 21).

For a cuboctahedron, the tile mosaic design on each face can be preconceived as a motif that repeats in a seamless pattern. Islamic geometric patterns are known to symbolically (and visually) represent infinity as they extend uninterruptedly on architectural surfaces. Surfaces of a polyhedron, all connected, hold potential to further this appearance of uninterrupted pattern. Informally, a pattern is uninterrupted whenever the line continuity inside the ornament appears to be never-ending. Starting to observe from a certain part of the pattern, the eyes of the beholder can trace the lines in a loop: an image of perpetuity. The planar developments of the cuboctahedra shown in Fig. 6 demonstrate the relations of the square and equilateral triangle faces and the patterns inside. When missing tiles are added, these two dimensional tilings can uninterruptedly continue as in Fig. 7.

The tiling of the faces of the cuboctahedron befits a periodic pattern that can also be constructed from a circular grid. Nevertheless, in this case the design on each face is a preconceived singular composition rather than a part of a pattern emerging

\footnotetext{
7 In medieval Anatolia where stone is the dominant material in monumental architecture, we see many unique pattern designs carved in stone. With the thirteenth century, new methods were devised for combining tiled decorations with the stone architecture. The tile mosaic technique is one of these techniques.
} 

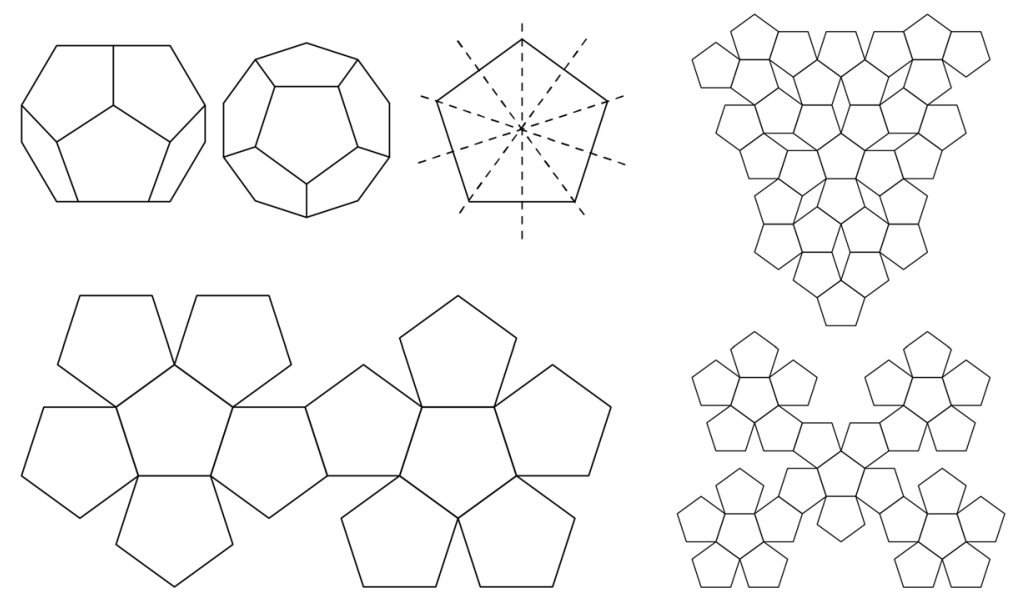

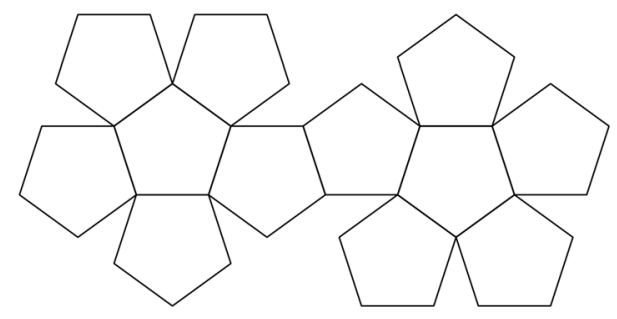

(a)

(b)

Fig. 8 a The dodecahedron, the single pentagonal face with corresponding symmetry axes, and the planar development of the solid; b Pentagonal tessellations readapted from Dürer (1525: 69)

from interlocking shapes. The effect of continuity is still sustained on the plane and hence all around the polyhedron. The advantage of this approach is the handling of individual tile mosaic pieces and applying them onto stone surfaces as one whole shape.

However, the process of applying a seamless pattern on the faces of a dodecahedron is not straightforward. The regular dodecahedron is one of the five Platonic solids and has twelve regular pentagonal faces; the planar development of a dodecahedron leaves rhombus-shaped gaps in other shapes in between its pentagons (Fig. 8). A pattern featuring regular pentagons requires additional polygons to cover the two-dimensional plane that the surfaces of the solid are developed onto (Dürer 1525: 69). Incidentally, a good number of continuous two-dimensional patterns with regular pentagons are not periodic.

The Tusi Atelier practiced both periodic and aperiodic patterns with pentagons. The literature on aperiodic patterns such as Penrose-like tilings in Islamic Art (Cromwell 2009: 36-56; Lu et al. 2007; Makovicky 1992: 67-86, 2016: 35-51) mostly suggests localized tiling systems and do not explain how and why artisans shift in methodology from constructing designs based on circular grids to those based on tiles. An investigation of the dodecahedron and the search for a suitable tessellation on it may lead to the development of a continuous pattern with pentagons. The material properties and techniques of the tile mosaic application already require the planar development of the polyhedra.

In applying an Islamic geometric pattern on the faces of a dodecahedron, one approach is to first project a periodic pattern onto a cube, and then translate it to the surfaces of the dodecahedron that cube is inscribed in. Most famously, this pattern can be Cairo tessellation (Thomas and Hann 2008: 101-103). Schattschneider et al. (1982: 26-27) provide an example to this approach by first covering a cube with 

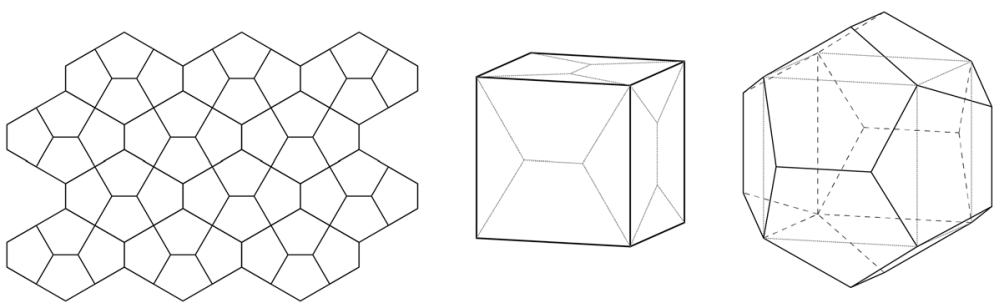

Fig. 9 Projecting a pattern onto a dodecahedron as adapted from Schattschneider et al. (1982: 26-27). A Cairo tessellation covering the faces of a cube is then projected onto the surfaces of a dodecahedron circumscribing it

Escher patterns based on Cairo tessellation. The shapes are then projected onto the surfaces of a dodecahedron that circumscribes the cube (Fig. 9).

\section{Patterns for the Dodecahedron of the Tomb of Gömeç Hatun}

Knowledge of polyhedral geometry is directly relevant to creating patterns with pentagonal symmetry. In recreating the possible pattern on the dodecahedra of the tomb of Gömeç Hatun, we initially relied on the remaining traces of tile mosaic on the surfaces of the portal adjacent to the polyhedra. Although there are no other examples known to us where the continuous patterns on the neighboring surfaces and the pattern on the faces of polyhedral column capitals match and we did not anticipate seeing the same design continue on the dodecahedron, we sought clues in these traces. Indeed, in whatever is left are found resembling polygons_-irregular pentagons to be exact-on the surfaces of both the dodecahedron and the bordering pattern above it (Fig. 10a). Yet there is simply not enough evidence to draw conclusions about the whole pattern on the dodecahedron. With reference to the literature (Schneider 1980: 117) and what is visible in the traces, we were able to complete a design for the remaining patterns on the bordering surface above (Fig. 10b). Following Meinecke (1976: II, 355-358), Schneider (1980: 182) refers to Pattern 277 in his catalogue as one from the iwan of the tomb of Gömeç Hatun. This particular pattern adapts well to the traces around the dodecahedron but does not complete the picture. Corners are anomalies. Pattern 348 from Schneider (1980: 131) is also suitable in certain parts of the remaining tile mosaic. What we have is a combination of these two patterns (Fig. 10b-d). Both 277 and 348 have pairs of irregular pentagons that group with a bowtie in motifs suggestive of Cairo tessellation. However, despite the similarity in visual vocabulary, it is not possible to extend this design seamlessly on the faces of the dodecahedron.

In an alternative approach, patterning a dodecahedron can basically involve twelve iterations of a design with fivefold ${ }^{8}$ symmetry, each fitting onto one of the

\footnotetext{
${ }^{8}$ In geometry, a continuous pattern design which decorates a surface by the regular repetition of a unit is examined by the symmetry operations presented in its structure. In this case, the design involves the rotation of the same unit five times, therefore a pattern with fivefold rotational symmetry. A geometric design has $n$-fold symmetry about a fixed point if, when rotated $360 / n$ degrees or $2 / n$ radians, the resulting image maps the pattern onto itself.
} 


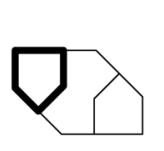

(a)
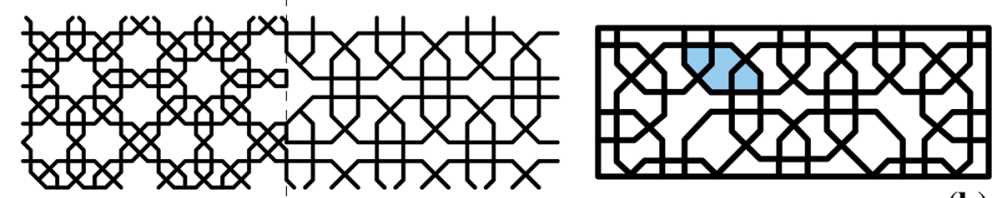

(b)
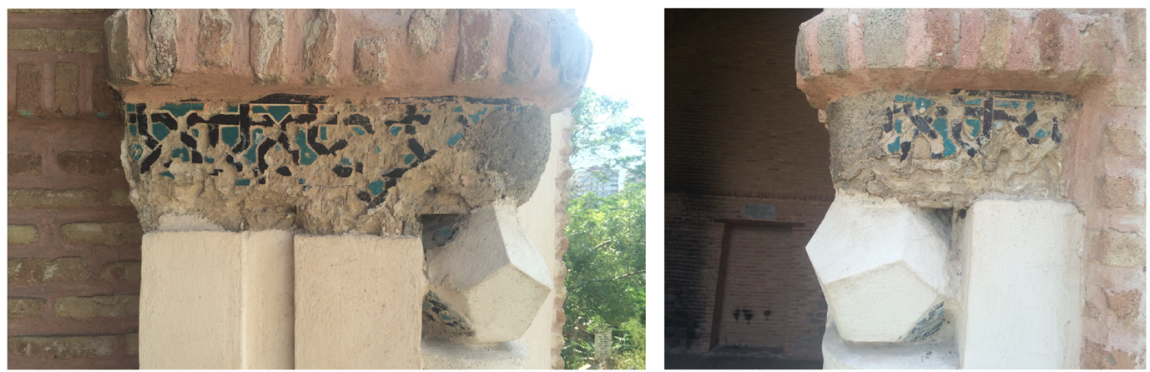

(c)
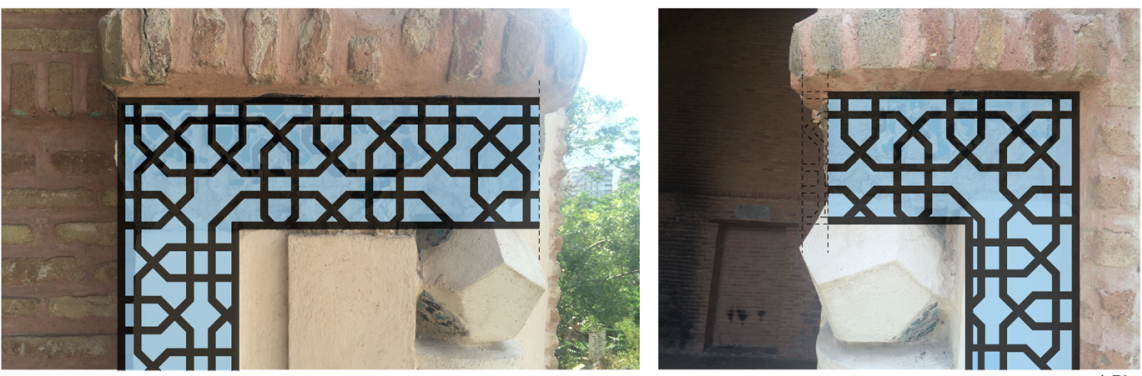

(d)

Fig. 10 Pattern design for the tiling based on the current condition. a Irregular pentagonal tiles are clearly visible inside the pattern traces; b Parts of Pattern 277 and Pattern 348, after (Schneider 1980: 117 and 131); c Current condition of the iwan d Proposals of the authors juxtaposed on the images

faces of the solid. The three seemingly uninterrupted patterns from the cuboctahedra cited earlier provide a base for adaptations. In each of those patterns, line continuity was preserved over the edges of polyhedra. We adapt their threefold symmetry to fivefold symmetry (Fig. 11). Specifically, we chose to adapt the designs on the triangular faces of the cuboctahedra, as the patterns on the square faces of the solids at Beyhekim and Eşrefoğlu Mosques display more refined, curved and floral characteristics unique to each design. Common to the patterns on the triangular faces in all three cuboctahedra is the central arrangement of groups of straight lines which can easily be reinterpreted when there are five sides instead of three.

Additionally, based on the visual clues remaining on the protected faces of the dodecahedron column capital, we complete two alternate designs (Fig. 12). The first one, developed in Fig. 12a, turns inside out the motif shown in Fig. 11b. The second one, developed in Fig. 12b, includes the irregular pentagon from the bordering pattern from above but does not form a seamless tessellation. All five designs 

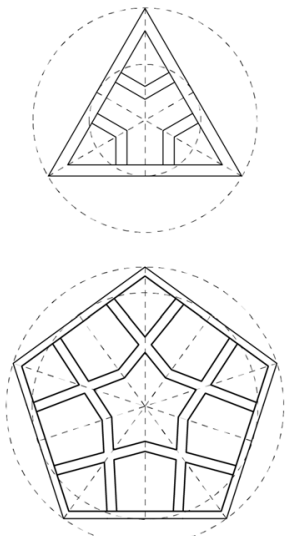

(a)
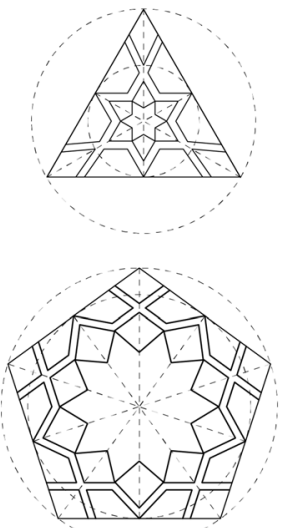

(b)
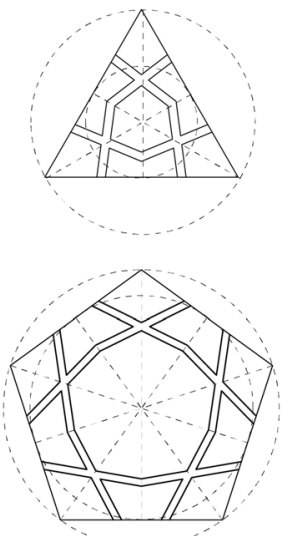

(c)

Fig. 11 Top row patterns from triangular faces of the cuboctahedra. Bottom row proposed designs for the pentagon based on the styles of the cuboctahedra of a Şifaiye Madrasah Portal; b Beyhekim Mosque; c Eşrefoğlu Mosque
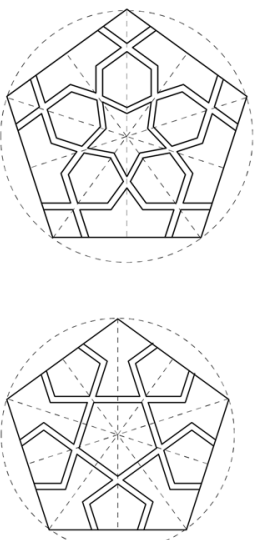
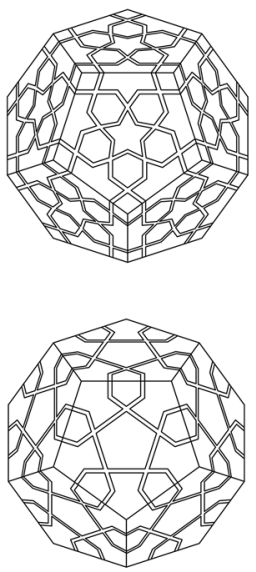

(a)
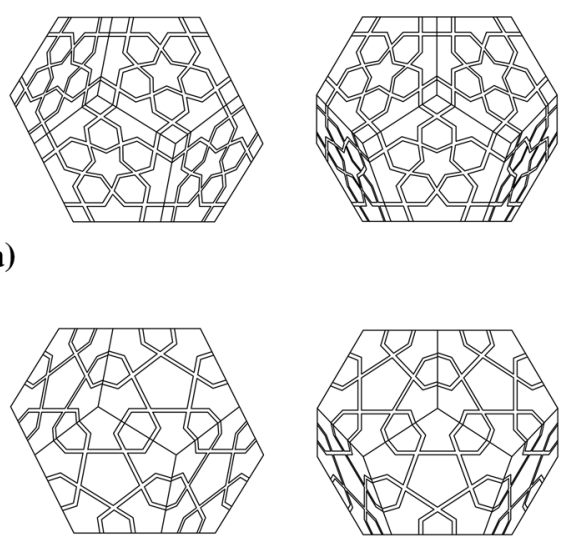

(b)

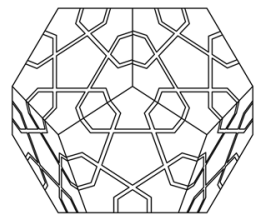

Fig. 12 Two alternate designs based on visual clues from the protected faces of the Gömeç Hatun dodecahedron column capital

(Figs. 11, 12) are based on existing visual vocabularies of design, albeit for different polygons.

The approach of designing the tile mosaic as individual faces of the dodecahedron rather than extending a planar design onto its developable surfaces, provides a sufficient and feasible basis for physically applying Islamic patterns onto the solid (Fig. 13). Still, the general design philosophy of this genre of patterns lies in the continuous pattern to the effect of infinity. 


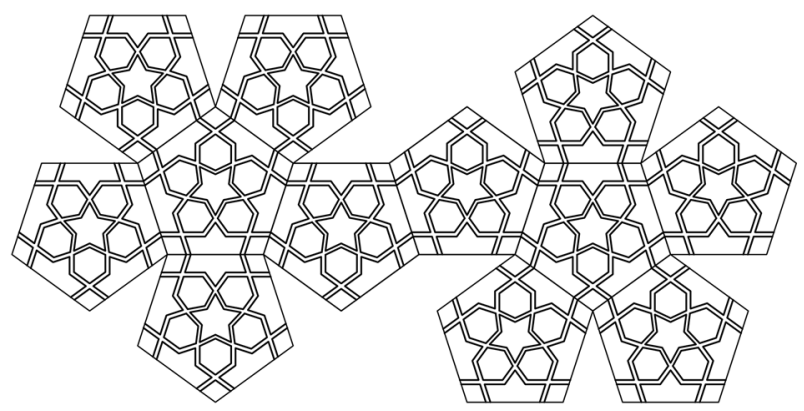

(a)

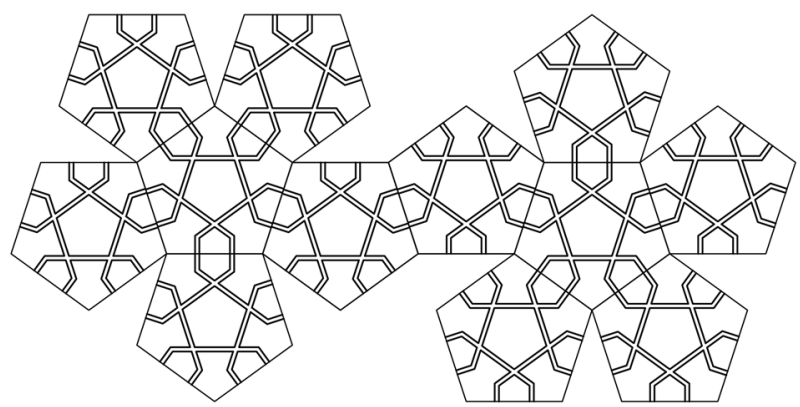

(b)

Fig. 13 The proposed pattern designs from Fig. 12 on the dodecahedron net

\section{Concluding on a Holistic View}

The use of polyhedra in Islamic architecture is not uncommon, yet examples where these polyhedra are covered with geometric patterns are rare. Almost all of the few examples from Seljuk Anatolia are cuboctahedron. The dodecahedra of the tomb of Gömeç Hatun corroborates the level of mathematical knowledge artisans were translating to construction.

Islamic geometric patterns are valued for a perceived effect of infinity. Even when extending on a variety of surfaces, they still sustain the effect. It is relevant to think that builders sought the same desire when applying patterns on polyhedra. The symbolic meaning of polyhedra for discussions concerning infinity, divinity and nature is deliberately left outside the scope of this paper. Adhering to limitations of one paper, it is assumed that only the uninterruptedness of the pattern yields the effect of infinity in this case, rather than the geometry of the solid. Instead, due attention was given to material processes of how these designs are constructed as they are not mere form exercises from a design point of view.

Designing and building a continuous pattern for a polyhedron both require a comprehension of the three-dimensional geometry of the solid as well as the symmetry axes of each individual surface. The knowledge of the dihedral angle and 
of the planar development of polyhedra are essential for constructing the solid itself. Cutting a dodecahedron out of a block of stone or building it out of glazed pentagonal tiles are sophisticated applications of mathematics at the time. And some examples top this with the challenge of ornamenting the faces of the polyhedra.

The pattern designs on various cuboctahedra and techniques applied in constructing them out of glazed tiles show that artisans of the medieval Anatolia possessed mathematical knowledge of solids and polygons together. Just as the patterns on larger architectural surfaces adhered to the borders, these designs took note of the edges of the polyhedra and how the faces connected, what angle they connected at, and their symmetry group. Edges connected continuing lines and allowed for spatially perceiving the visual field of continuity. There is an informed translation of the two-dimensional geometry to a three-dimensional one.

A suitable design for a dodecahedron differs from those for cuboctahedra, as gaps appear when the surfaces of the solid is unfolded onto a plane. The thirteenthcentury example of the tomb of Gömeç Hatun provides a unique instance of a twodimensional pattern with pentagons covering the surfaces of a dodecahedron. With little physical evidence from the current condition of the monument, we rely on the related literature and cuboctahedral examples of the same style in order to hypothesize how this design may have been realized.

The builders and artisans of the time and region approached their tasks in a holistic manner, understanding the relations between shapes in two and threedimensions, and across different scales. The tomb of Gömeç Hatun displays visual motifs that repeat as a basic vocabulary simultaneously used in the form of the plan, the profile of the portal and in geometric patterns on the portal. This ubiquity suggests a holistic undertaking of the architectural design of the monument and supports the transference of design vocabulary across two-dimensional and threedimensional elements of the design. The builders were consciously comparing, adapting, reapplying a design know-how across decades and geographies, between projects and within different aspects of the same project. The design know-how included not only the visual design vocabulary but also techniques and mathematical knowledge that allowed them to materialize the design. The sophistication of the holistic and consistent undertaking in designing the form of the building as well as in the application of a geometry of polygons and polyhedra in the tradition of the Tusi Atelier provides an insight to the design knowledge, method and thinking available at that time and in that place.

Acknowledgements This research is supported by The Scientific and Technological Research Council of Turkey (TÜBITAK) under the project number 114K283, and under the 2211-Scholarship for $\mathrm{PhD}$ students program. All photographs and images are by authors except where noted. The assistance and kind interest of Prof. Dr. Ali Baş, Prof. Dr. Osman Eravşar and Dr. Şükrü Dursun in the research of historical photographs and references are gratefully acknowledged. We thank Konya Municipality, Department of Housing and Urban Development and Konya Cultural and Natural Heritage Preservation Board for providing restoration reports and drawings of the Gömeç Hatun Tomb. We also want to express our gratitude to Prof. Dr. Semra Ögel and Akbank for permission to reproduce the photo that appears here and to Şule Yiğit for hosting us in her studio for the making of the dodecahedron out of a clay cube. 


\section{References}

Al-Būzjānī, Abu'l-Wafā. ca. 940-998, Kitab F̄̄ mā yahtaj ilayhi al-șāni' min al-a 'māl al-handasiyya (On the Geometric Constructions Necessary for the Artisan). Istanbul, Süleymaniye Kütüphanesi (Süleymaniye Library), Ms. Ayasofya 2753.

Bakırer, Ömür. 1999. The Story of Three Graffiti. Muqarnas 16: 42-69.

Critchlow, Keith. 1976. Islamic Patterns: An Analytical and Cosmological Approach. London: Thames \& Hudson.

Cromwell, Peter. R. 1999. Polyhedra. Cambridge: Cambridge University Press.

Cromwell, Peter. R. 2009. The search for quasi-periodicity in Islamic 5-fold ornament. Math. Intelligencer 31 no 1: 36-56.

Dazkırlı, Tuncer. 2008. Konya İli, Medrese Mahallesi Musalla Mezarlığı İçerisinde Gömeç Hatun Türbesi Rölöve, Restitüsyon ve Restorasyon Projesi Raporlarl, Fotoğraflar. Unpublished restoration report. Konya municipality, department of housing and urban development.

Dürer, Albrecht. 1525. Underweysung der Messung mit dem Zirckel und Richtsheyt in Linien, Ebnen, und gantzen Corporen (Vol. 4). Facs. rpt. Portland: Collegium Graphicum, 1972.

Hankin, E. H. 1925. Examples of methods of drawing geometrical arabesque patterns. The Mathematical Gazette 12: 371-373.

Kappraff, Jay. 1992. The Relationship between Mathematics and Mysticism of the Golden Mean through History. In: Fivefold Symmetry, ed. István Hargittai, 33-66. Singapore: World Scientific.

Lee, A. J. 1987. Islamic star patterns. In Muqarnas IV: An Annual on Islamic Art and Architecture, ed. Oleg Grabar, 182-197. Leiden: E.J. Brill.

Lu, Peter J. and Paul J. Steinhardt. 2007. Decagonal and Quasi-Crystalline Tilings in Medieval Islamic Architecture. Science 315 (February 2007): 1106-1110.

Lundy, Miranda. 2010. Schönheit der Geometrie. Mannheim: Artemis \& Winkler.

Makovicky, Emil. 1992. 800-year-old pentagonal tiling from Maragha, Iran, and the new varieties of aperiodic tiling it inspired. In: Fivefold symmetry, eds. István Hargittai, 67-86. Singapore: World Scientific.

Makovicky, Emil. 2016. On the Kond style of Islamic tiling: a study in practical Islamic geometry. Rendiconti Lincei, Scienze Fisiche e Naturali 28 (1): 35-51.

Malkevitch, Joseph. 2013. Milestones in the history of polyhedra. In: Shaping Space, eds. Marjorie Senechal, 53-63. New York: Springer.

Meinecke, M. 1976. Fayencedekorationen seldschukischer Sakralbauten in Kleinasien, 2 vols. 1. Text und Tafeln; 2. Katalog. Tübingen: Wasmuth.

Necipoğlu, Gülruğ. 1995. The Topkapi Scroll-Geometry and Ornament in Islamic Architecture: Topkapi Palace Museum Library MS H. 1956. Santa Monica-California: The Getty Center for the History of Art and the Humanities.

O'Rourke, Joseph. 2013. Milestones in the History of Polyhedra. In: Shaping Space: Exploring Polyhedra in Nature, Art, and the Geometrical Imagination, ed. Marjorie Senechal, 53-63. New York: Springer.

Ögel, Semra. 1994. Anadolu'nun Selçuklu çehresi. İstanbul: Akbank Yayınları.

Önkal, Hakkı. 1996. Anadolu Selçuklu Türbeleri. Ankara: Atatürk Kültür, Dil Ve Tarih Yüksek Kurumu Atatürk Kültür merkezi Yayını.

Özdural, Alpay. 1995. Omar Khayyam, Mathematicians, and "Conversazioni” with Artisans. Journal of the Society of Architectural Historians, 54(1): 54-71.

Pace, B. 1926. Ricerche Nella Regione Di Conia Adalia e Scalanova. Annuario Della R. Scuola Archeologica di Atene VI-VII: 343-393.

Rigby, J. 2005. A Turkish Interlacing Pattern and the Golden Ratio: Whirling Dervishes and a Geometry Lecture in Konya. Mathematics in School 34(1): 16-24.

Sarhangi, Reza. 2008. Illustrating Abu al-Wafā' Būzjānī: Flat Images, Spherical Constructions. Iranian Studies 41(4): 511-523.

Schattschneider, Doris and Wallace Walker. 1982. M.C. Escher. Kaleidocycles. Norfolk, Tarquin Publications. 3rd ed.

Schneider, Gerd. 1980. Geometrische Bauornamente der Seldschuken in Kleinasien. Wiesbaden: Reichert.

Scriba, Christof J. and Peter Schreiber. 2015. 5000 Years of Geometry: Mathematics in History and Culture. Basel: Springer.

Sözen, Metin. 1968. Anadolu'da Eyvan Tipi Türbeler. Anadolu Sanatı Araştırmaları 1: 167-210. 
Thomas, B. G. and Hann, M. A. 2008. Patterning by Projection: Tiling the Dodecahedron and other Solids. In Bridges Leeuwarden: Mathematical Connections in Art, Music, and Science, eds. Reza Sarhangi and Carlos Séquin, 101-108. http://archive.bridgesmathart.org/2008/bridges2008-101.pdf. Accessed 10 April 2017.

Uğur, Mehmet F. 1937. Gömeçhane, Konya Halkevi Dergisi 9: 567-570.

Yetkin, S. K. 1961. The Turbah of Gumaç Hatun, a Seljūk Monument. Ars Orientalis 4: 357-360.

Sibel Yasemin Özgan is a PhD Candidate in the Architectural Design Computing Program at Istanbul Technical University, where she works as a research and teaching assistant in the Department of Interior Architecture. She teaches undergraduate level design studios and some elective courses. Her research interest lies in the relation of computation to histories of culture, arts, crafts and architecture as well as the history of computational design thinking. She was a visiting scholar in the University of Fine Arts in Berlin, Germany in 2016-2017.

Mine Özkar is a professor of architecture at Istanbul Technical University, where she is the coordinator of the Graduate Program in Architectural Design Computing. She earned her PhD in design and computation from MIT. In some of her previous work, she has interpreted the history and theory of progressive pedagogy in art and design from a computational perspective. Her current research focuses on shapes, $\mathrm{visual} / \mathrm{spatial} / \mathrm{material}$ computation, and design methods as well as the integration of foundational design education and computational knowledge. She is a member of the Editorial Board of the Nexus Network Journal. 